\title{
Flight Tunnel Responses of Female Grape Berry Moth (Paralobesia viteana) to Host Plants
}

\author{
Dong H. Cha • Stephen P. Hesler • Charles L. Moser • \\ Satoshi Nojima • Charles E. Linn Jr.• \\ Wendell L. Roelofs • Gregory M. Loeb
}

Received: 16 November 2007 /Revised: 24 January 2008 / Accepted: 28 March 2008 / Published online: 26 April 2008

(C) Springer Science + Business Media, LLC 2008

\begin{abstract}
Semiochemicals play important roles in mate and host recognition of herbivorous insects, such as moths, and flight tunnels have been an effective tool in the identification of these bioactive compounds. However, more work has been carried out on pheromones than on host plant cues, and few examples exist where flight tunnel evaluations of host cues have resulted in a lure that is attractive under field conditions. Our goal was to determine whether the flight tunnel could be used to evaluate the response of a specialist moth, grape berry moth (GBM), to its host plant (grapevines), by incorporating ecological and physiological aspects of GBM biology. We found grape shoot tips and mature leaves were more attractive to female GBM than unripe and ripe berries or flowers. Under optimized flight tunnel conditions, approximately $80 \%$ of tested females flew upwind and closely approached or landed on the most preferred target. Mating status, wind speed, the time of day, and the presence/absence of patterns that resemble grape tissues on the top of the flight tunnel all significantly affected the responses of female GBM. Consideration of these factors in flight tunnel assays will aid in the development of a synthetic lure that can be used to monitor female moths in the field.
\end{abstract}

D. H. Cha $\cdot$ S. P. Hesler $\cdot$ C. L. Moser $\cdot$ S. Nojima

C. E. Linn Jr. · W. L. Roelofs $\cdot$ G. M. Loeb $(\triangle)$

Department of Entomology, Cornell University,

630 W. North St., NYS Agricultural Experimental Station,

Geneva, NY 14456, USA

e-mail: gme1@cornell.edu

Present address:

S. Nojima

Department of Entomology,

North Carolina State University,

Raleigh, NC 27695, USA
Keywords Flight tunnel P Paralobesia viteana - Vitis spp. Host volatiles · Tortricidae

\section{Introduction}

Moth species in the family Tortricidae cause economic losses in agricultural and horticultural crops and forests in temperate regions worldwide (Van der Geest and Evenhuis 1991). Semiochemicals play important roles in both mate and host recognition in these moths (Ridgway et al. 1990; Bruce et al. 2005). Sex pheromones have been identified in over 60 tortricids (Arn 1991) and used in the field for control or monitoring purposes. Similarly, host plant volatiles that are involved in host recognition or oviposition have been studied with a focus on female tortricids (Reed and Landolt 2002; Ansebo et al. 2004; Hern and Dorn 2004; Natale et al. 2004; Tasin et al. 2005, 2006a, b, 2007). Most of the behavioral components of these studies have been carried out in flight tunnels since this type of bioassay is a useful method to evaluate the responses of flying insects to semiochemicals (Howse et al. 1998). However, most of the research using flight tunnels has been looking at responses to sex pheromones, and there is considerably less on responses to host plant cues (e.g., Cardé 1984). This could be because male moths generally have more obvious behavioral responses to pheromone, whereas females have rather subtle behavioral responses to host cues (Tasin et al. 2006b), thus making identification of such bioactive compounds difficult. This may explain why few flight tunnel evaluations of host cues, especially for lepidopterans, have resulted in a lure that works in the field (e.g., Ansebo et al. 2004). In addition, plants generally emit a greater number of volatile compounds than found in insect pheromones, making identification of key compounds more difficult. This situation has been improved 
recently with the development of volatile collection systems, such as solid phase microextraction in combination with gas chromatographic-electroantennographic detection (e.g., Zhang et al. 1999; Nojima et al. 2003a, b).

Grape berry moth (Paralobesia viteana) (GBM), a major specialist pest of cultivated grape in the Eastern USA, is crepuscular in activity (Taschenberg 1945). Although the female-produced sex pheromone of GBM has been known for several decades (Roelofs et al. 1971) and used to monitor male flight activity, male captures in these pheromone traps have proven to be poorly correlated with female activity (Hoffman 1990; Weigle et al. 1999). Consequently, trap catch data from pheromone traps have not been useful for timing management decisions. As a first step towards developing a host-plant-based lure that is effective in the field, our goal was to determine whether female GBM respond to plant sources in the flight tunnel by comparing response to different grape tissues (flowers, unripe berries, ripe berries, mature leaves, and shoot tips) since knowing the most attractive plant part would help in future studies to identify bioactive volatile cues used for host location. We also examined the effects of time of day, ceiling pattern, wind speed, and mating status on female behavioral responses.

\section{Materials and Methods}

Insect Grape berry moths were reared in cages placed in walk-in environmental chambers at $26^{\circ} \mathrm{C}$ and $60 \% \mathrm{RH}$ under an 18:6 (L:D) photoperiod. Adult moths were fed with $50 \%$ honey and water impregnated in cotton. They mated freely in rearing cages $(45 \mathrm{~cm}$ height $\times 77 \mathrm{~cm}$ width $\times$ $45 \mathrm{~cm}$ diameter) and oviposited on seedless grape (Vitis vinifera, red flame variety). First and second instars were transferred to diet cups $(30 \mathrm{ml}$, WinCup Inc., Stone Mountain, GA, USA) and reared on semi-synthetic diet (Nagarkatti et al. 2000) consisting of grapes, pinto beans, and commercially available tobacco hornworm diet (BioServe, Frenchtown, NJ, USA). Pupae were sexed and set up in cohorts for flight tunnel bioassays. Each cohort was set up with $10-15$ female pupae in a Plexiglas cage $(30 \mathrm{~cm}$ height $\times 30 \mathrm{~cm}$ width $\times 30 \mathrm{~cm}$ diameter) and provided with $50 \%$ honey and water. For mated cohorts, females were housed in cages with 15 to 20 males (one antenna clipped for distinction from females) and a grape cluster to increase mating. Both 3-day-old virgin females and 5-day-old mated females were used for flight tunnel bioassays.

Flight Tunnel The response of female GBM to host plants under different conditions was assessed by using two different, but similarly designed flight tunnels. Both flight tunnels were $2 \mathrm{~m}$ in length by $0.6 \mathrm{~m}$ in width and $0.6 \mathrm{~m}$ in height with a fan installed at the upwind end to create a steady airflow into the tunnel and an exhaust hood at the downwind end to evacuate odor from the flight tunnel and laboratory through a vent. The upwind and downwind ends of the tunnel consisted of two layers of cheesecloth to prevent escape of moths. The first tunnel was constructed with glass doors on one long side and a white panel on the other and a Plexiglas floor and ceiling. A black stripe floor pattern $(1.5 \mathrm{~cm}$ width stripes every $19 \mathrm{~cm}$ perpendicular to the direction of airflow) over a white surface was installed under the Plexiglas floor. Light was provided from above with eight 40-watt incandescent bulbs. Light intensity was reduced to $25 \mathrm{~lx}$ (using a rheostat and measured with a Sunlight Illumination Meter, Weston Instruments Inc., Archbald, PA, USA) to mimic dusk conditions. We used this tunnel initially to quantify the most attractive grape tissue type to female GBM, and to investigate the importance of diel periodicity, additional optomotor cues, and wind speed. We conducted subsequent bioassays in an all-glass flight tunnel to minimize volatile contamination in anticipation of future work to identify specific volatile cues used by female GBM. The second flight tunnel was used to determine the effect of mating status on the flight response of female GBM. Light (again at $25 \mathrm{~lx}$ ) was provided by eight 25 -watt incandescent bulbs, and the pattern on the glass floor was made up of randomly distributed dark green paper circles $(10 \mathrm{~cm}$ diameter) on a white background. During the experiments, temperature and relative humidity of the first flight tunnel was $23.3^{\circ} \mathrm{C}( \pm 0.64$ STD $)$ and $30.6 \%( \pm 7.71 \mathrm{STD})$, and $23.0^{\circ} \mathrm{C}( \pm 0.32 \mathrm{STD})$ and $23.6 \%$ $( \pm 0.16$ STD) in the second.

We tested the response of small groups (four to six) of females in the trials conducted in the first flight tunnel, recording the behavior of each moth in the group for $15 \mathrm{~min}$. Flight behavior was made by two observers. We tested single female moths for trials conducted in the second flight tunnel, recording behavior for $8 \mathrm{~min}$ per moth. We noted the time it took each moth to respond, and the behavior expressed: leaving the release cage or making an orientation flight (more than $50 \mathrm{~cm}$ of tight zigzag flight to within $10 \mathrm{~cm}$ of the target, similar behavior as observed in flights with pheromone lure) or contacting the target. For data analysis, we categorized each moth based on the best behavior that the moth displayed within the duration of each assay. Thus, moths that flew from the release cage were categorized as "no orientation" (no directed flight toward the target), "orientation," or "landing". The target for a particular trial was introduced at the upwind end in the center of tunnel (30 $\mathrm{cm}$ from upwind end) affixed on an acetone-washed copper tube stand, while females were introduced in the plume about $1.5 \mathrm{~m}$ downwind of the target in small metal screen cages. The pattern and movement of smoke from incense placed at the target end 
of the tunnel was used to determine the female moth release point.

Response of Female Moths to Host plants We compared the response of female GBM to flowers, unripe berries, ripe berries, mature leaves, or shoot tips (three to four immature leaves with tendrils) of Vitis labrusca (variety concord). All grape plants were grown from cuttings in 1-gal pots under greenhouse conditions at $21-26^{\circ} \mathrm{C}$, with supplemental light extending the day length to 14 to $16 \mathrm{~h}$. They were fertilized weekly with water-soluble fertilizer (Peters 20-20-20, Scotts-Sierra Horticultural Products Co., Marysville, OH, USA). Grape tissue was harvested and immediately placed into a water pick just prior to the start of assays. The volume of each tissue type presented had an approximate area of $10 \times 10 \times 10 \mathrm{~cm}$. A portion of the grapevine stem was retained for all types of tissue used in the flight tunnel. Control flights were performed by using the acetonewashed copper stand without water pick as a target. The effect of mating status on flight response of female GBM was examined by using concord shoot tips as the target. We performed both experiments (tissue type and mating status) under optimized flight tunnel conditions defined by experiments described below.

Effect of Environmental and Physiological Factors on Flight Tunnel Responses In all tests, except where noted, we used live concord shoot tips as a target. The effects of diel periodicity on female flight were tested by comparing flight responses of mated and unmated females to shoot tips at dusk (in our experiment, this was a 2-h period including the hour before and after the start of the scotophase) and 2$4 \mathrm{~h}$ before dusk. The response of female GBM with a ceiling pattern was assessed by adding pieces of dark green paper, cut in the shape of grape leaves, on the glass ceiling below the light source, thereby creating a pattern of dark shapes that filled approximately $25 \%$ of the surface. We tested the effect of wind speed by adjusting the fan with a rheostat to create velocities of $0.25,0.5$, or $0.66 \mathrm{~m} / \mathrm{s}$ (measured with a vaneometer from Dwyer Instruments, Inc., Michigan City, IN, USA) at the point of release for the moths.

Statistical Analyses The effect of tissue type $(N=238)$, time of day $(N=46)$, wind speed $(N=25)$, ceiling pattern $(N=30)$, and mating status $(N=127)$ was analyzed by using generalized linear models with orientation or landing as dependent variables and time, wind speed, ceiling pattern, tissue type, or mating status as fixed independent variables by using binomial distribution with logit link function and maximum likelihood estimation (Proc Glimmix, SAS Institute 2006). Test effects were compared by using contrast statements and mean $\%$ response and standard errors were estimated with lsmeans statement with ilink option and presented in the figures (Proc Glimmix, SAS Institute 2006). We interpreted our results as odds ratios where odds are defined as the ratio between probability of event and probability of no event (Allison 2001). Odds were calculated by exponentiating coefficients of independent variables in Proc Glimmix output.

\section{Results}

Orientation to Different Tissue Types Females responded differently to different tissue types in terms of orientation $(P<0.001)$ and landing $(P<0.001)$ (Fig. 1). Females displayed the greatest level of orientation and landing to shoot tips, but this was not statistically different from the response to mature leaves ( $P=0.27$ for orientation, $P=0.17$ for landing). Shoot tips were more attractive to females than unripe berries $(P=0.014$ for orientation, $P=0.051$ for landing), which in turn were more attractive than ripe berries ( $P=0.012$ for orientation, $P<0.001$ for landing) and flowers ( $P=0.004$ for orientation, $P=0.011$ for landing). Ripe berries were not different from flowers $(P=0.13$ for orientation, $P=0.55$ for landing) although they were more attractive from control with respect to orientation $(P=$ $0.014)$ but not landing. Attractiveness of flowers to females was not different than control $(P=0.26$ for orientation, $P=$ 0.63 for landing).

Effects of Diel Periodicity on Flight Behavior The proportion of females that oriented to $(P=0.010)$ and landed on

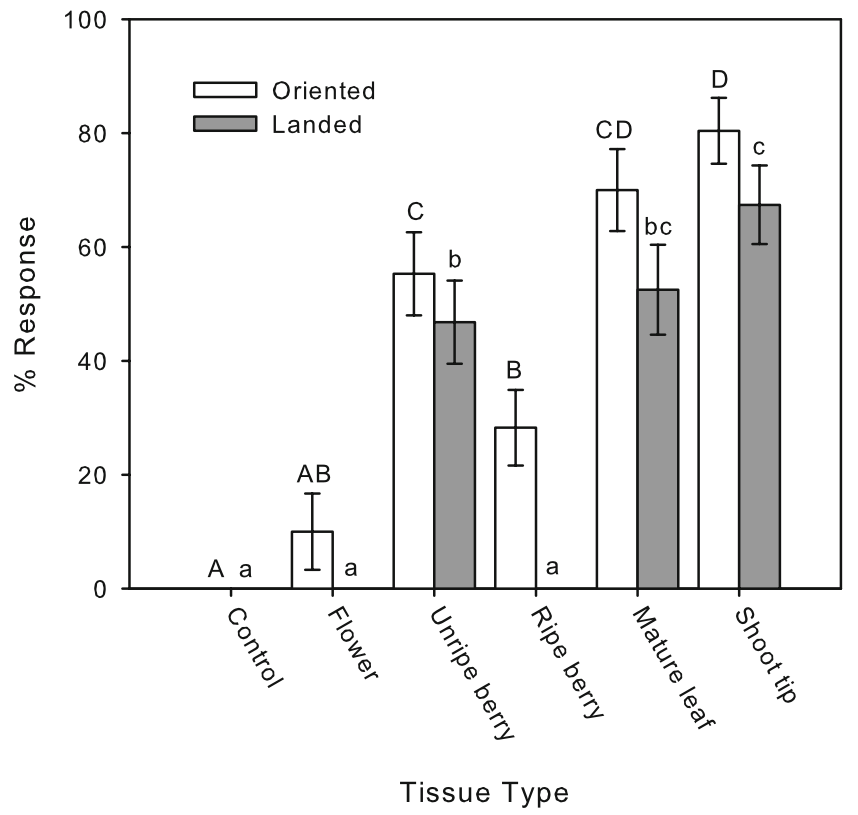

Fig. 1 Flight tunnel response (\%) of female GBMs to different parts of the host plant, $V$. labrusca. Different letters (capital letters for orientation response and small letters for landing response) on bars indicate significant differences $(P<0.05)$. Error bars $= \pm 1 \mathrm{SE}$ 
Fig. 2 Flight tunnel response (\%) of female GBMs to shoot tips of $V$. labrusca when a flown at dusk (between $1 \mathrm{~h}$ before and after dusk time) or 2-4 h before dusk, b flown with or without a ceiling pattern, $\mathbf{c}$ flown at different wind speeds $(0.25,0.5$, and $0.66 \mathrm{~m} / \mathrm{s}$ ), and $\mathbf{d}$ either virgin or mated. Different letters (capital letters for orientation response and small letters for landing response) on bars indicate significant differences $(P<$ $0.05)$. Error bars $= \pm 1 \mathrm{SE}$

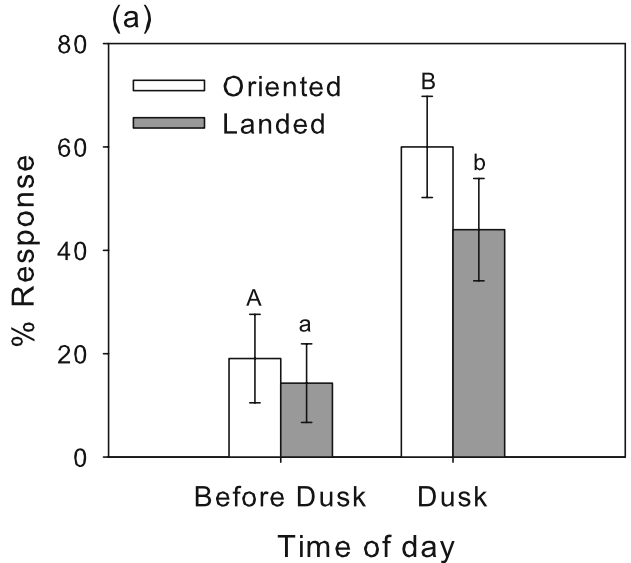

(c)

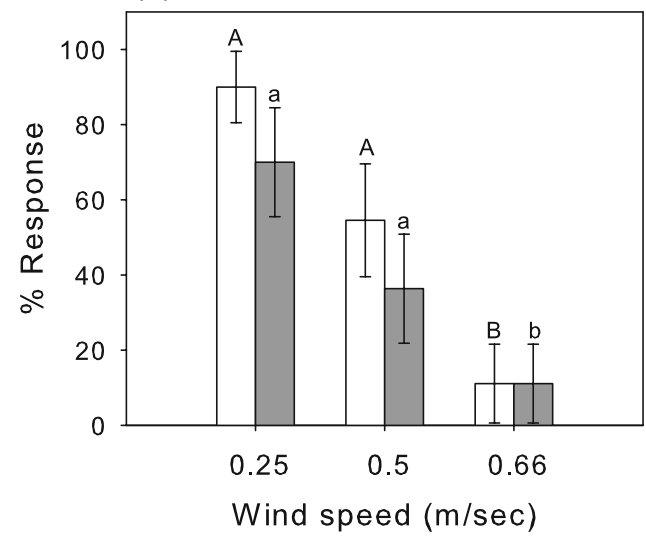

(b)

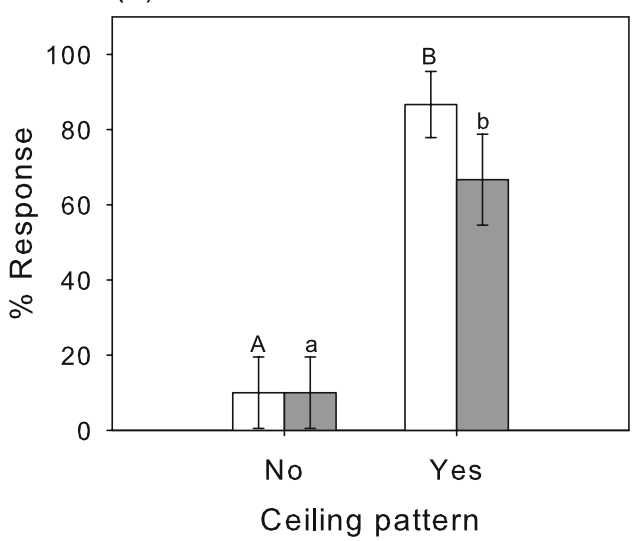

(d)

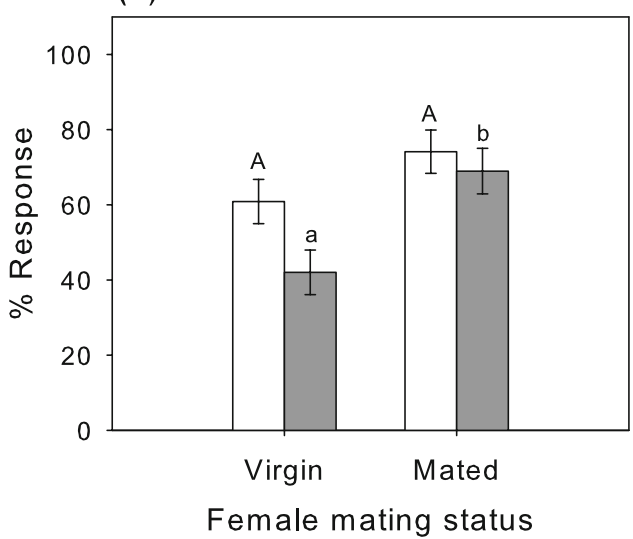

shoots $(P=0.043)$ was significantly higher at dusk than moths flown 2-4 h before dusk (Fig. 2a).

Effects of Flight Tunnel Environment The addition of a ceiling pattern to the flight tunnel increased the proportion of females orientating $(P=0.014)$ to and landing on $(P=$ $0.041)$ grape shoots compared to the control (Fig. 2b). The effect of wind speed was marginally important for both orientation $(P=0.050)$ and landing $(P=0.103)$ responses of females to grape shoots (Fig. 2c) with significantly fewer females responding at $0.66 \mathrm{~m} / \mathrm{s}$ than at the lower wind speeds.

Effect of Mating Status on Female Flight Behavior The mating status of females did not affect the orientation response $(P=0.150)$ but more mated females landed at the source than virgins $(P=0.015)$ (Fig. 2d).

\section{Discussion}

We compared attractiveness of different grape tissue types to female GBM as a first step in our effort to identify attractive host volatiles. Under the optimized flight tunnel condition determined by this study, we found that shoot tips and mature leaves are the two most attractive tissue types to female GBM. This appears somewhat counter intuitive, given that females lay eggs mostly on grape clusters. However, it is possible that they use shoot odors (shoot tips and mature leaves) to orient to the vines over long distances (several meters or more) but use different cues, including visual and chemotactile cues, to locate oviposition sites once within the canopy. We found that adjusting flight tunnel factors, such as wind speed and optomotor cues, along with consideration of biological factors, such as diel periodicity and mating status, can significantly impact on the orientation and landing responses of females. We observed that females had four to six times greater chance of locating the target around dusk than 2-4 h before dusk, which is not really surprising given that GBM is a crepuscular species and oviposition activity also peaks at dusk (Taschenberg 1945; Greg Loeb, unpublished data). Our findings are similar to those reported for the European grapevine moth, where responses to the host plant in the flight tunnel were significantly lower $6 \mathrm{~h}$ prior to dusk than at dusk (Hurtrel and Thiery 1999).

The addition of a ceiling pattern in addition to the existing one on the floor significantly increased orientation and landing female responses. In a previous study, male 
spruce budworm moths responded better to sex pheromone in a flight tunnel with a ceiling compared to a floor pattern (Sanders et al. 1981). However, we did not compare the response of females when only a ceiling pattern was used.

In our study, the behavior of females improved as wind speed decreased. This might be because wind speed affects plume structure, which is important in the flight of moths (Willis and Baker 1984; Vickers and Baker 1992). In addition, the size of the odor active space and the maximum distance of communication decrease at higher wind speed (reviewed in Elkinton and Cardé 1984). Moreover, GBM is small and does not appear to be a strong flyer, and may have difficulty maintaining upwind flight in even moderate wind. Indeed, Botero-Garces and Isaacs (2004) found that movement of marked GBM in the field was greatly reduced at wind speeds of $0.6 \mathrm{~m} / \mathrm{s}$.

Mating is an important event in a moth's life and brings about many physiological and behavioral changes (Thompson and Pellmyr 1991). Our interest was to test whether mated and unmated females showed different flight responses to host plants in the flight tunnel. We found that mated females had a better chance of landing on grape shoots compared to unmated female moths, although there was no difference in the incidence of orientation. There is the potential that our results from the mating status experiment are confounded because mated moths were 5 days old while unmated moths were 3 days old. However, in separate experiments evaluating orientation to volatile blends, unmated 3-day-old females were not different than unmated 5-day-old females (Dong Cha, unpublished data), suggesting a minimal confounding effect between age and mating status in our experiment. In addition, the importance of mating status in the behavior of other Tortricidae moths (e.g., oviposition site selection of eastern spruce budworm moth described by Wallace et al. (2004)) supports our result.

Other studies with tortricid moths also have shown a similar increase in landing response by mated females (Hurtrel and Thiery 1999; Yang et al. 2005; Masante-Roca et al. 2007). This might be because mated females are ready to oviposit, and landing may indicate a transition from host searching to oviposition-related behaviors. Increased levels of landings by mated females could have resulted from being previously exposed to odors of grape clusters present in our cohort mating cages. Improved flight response in mated females pre-exposed to tansy flower volatile has been reported in European grapevine moth (Hurtrel and Thiery 1999). However, in our environmental chamber, air moved freely among rearing and cohort chambers, so mated and unmated moths should have shared all the volatiles in the air. Thus, it would appear probable that physiological and neurological changes that follow mating could explain the increased probability of females landing.
The flight tunnel has proved to be an essential tool in developing a synthetic lure for the sex pheromone where the bioassay system relates well to what is happening in the field. Our finding showing that female GBM respond to host plant volatiles, especially under optimized flight tunnel conditions, suggests it has potential to develop synthetic host plant lures. We will be using this approach for future tests on isolated volatiles, as these tools will help in our efforts to improve a GBM monitoring system for use in management of this key grape pest.

Acknowledgements We thank Sara Villani, Eric Smith, Shinyoung Park, Rachel Tucker, Mike Colizzi, Jessica Worden, and Kevin Conley for their support on various aspects of this research, but particularly their efforts in maintaining the GBM colony and setting up mating cohorts. This research was supported by USDA NRI grant no. 200535302-16154 and USDA Viticultural Consortium.

\section{References}

Allison, P. D. 2001. Logistic Regression Using the SAS System: Theory and Application. SAS Institute, Cary, N.C.

Ansebo, L., Coracini, M. D. A., Bengtsson, M., Liblikas, I., RAMirez, M., Borg-Karlson, A. K., TAsin, M., and WitZGall, P. 2004. Antennal and behavioural response of codling moth Cydia pomonella to plant volatiles. J. Appl. Entomol. 128:488-493.

ARN, H. 1991. Sex pheromones, pp. $187-208$ in L. P. S. Van der Geest and H. H. Evenhuis (eds.). Tortricid Pests. Their Biology, Natural Enemies and Control. Elsevier, New York, NY.

Botero-Garces, N., and IsAaCS, R. 2004. Movement of the grape berry moth, Endopiza viteana: displacement distance and direction. Physiol. Entomol. 29:443-452.

Bruce, T. J. A., WADHAMS, L. J., and WoOdCOCK, C. M. 2005. Insect host location: a volatile situation. Trends. Plant Sci. 10:269-274.

CARDÉ, R. T. 1984. Chemo-orientation in flying insects. pp. 111-124, in W. J. BELL and R.T. CARDÉ (ed.). Chemical Ecology of InsectsChapman and Hall, London, UK.

Elkinton, J. S., and CARDÉ, R. T. 1984. Odor dispersion, pp. 73-91, in W. J BELL, and R.T. CARDÉ (eds.). Chemical Ecology of InsectsChapman and Hall, London, UK.

Hern, A., and Dorn, S. 2004. A female-specific attractant for the codling moth, Cydia pomonella, from apple fruit volatiles. Naturwissenschaften 91:77-80.

HOFFMAN, C. J. 1990. Development and validation of a risk assessment program for the management of grape berry moth, Endopiza viteana (Clemens), in New York state. PhD Dissertation, Cornell University, Ithaca, NY.

Howse P., Stevens, I., and Jones, O. 1998. Insect Pheromones and Their Use in Pest Management. Chapman \& Hall, London, UK.

Hurtrel, B., and THIERY, D. 1999. Modulation of flight activity in Lobesia botrana Den. and Schiff. (Lepidoptera: Tortricidae) females studied in a wind tunnel. J. Insect Behav. 12:199-211.

Masante-Roca, I., Anton, S., Delbac, L., Dufour, M.-C., and GADENNE, C. 2007. Attraction of the grapevine moth to host and non-host plant parts in the wind tunnel: effects of plant phenology, sex, and mating status. Entomol. Exp. Appl. 122:239-245.

Nagarkatti, S., MuZa, A., and Saunders, M. 2000. Meridic diet for Endopiza viteana (Lepidoptera: Tortricidae). Can. Entomol. 132:259-261. 
Natale, D., Mattiacci, L., Pasqualini, E., and Dorn, S. 2004. Apple and peach fruit volatiles and the apple constituent butyl hexanoate attract female oriental fruit moth, Cydia molesta, in the laboratory. J. Appl. Entomol. 128:22-27.

NoJima, S., LinN, C, and RoElofs, W. 2003a. Identification of host fruit volatiles from flowering dogwood (Cornus florida) attractive to dogwood-origin Rhagoletis pomonella flies. J. Chem. Ecol. 29:2347-2357.

Nojima, S., Linn, C., Morris, B., Zhang, A. J, and Roelofs, W. 2003b. Identification of host fruit volatiles from hawthorn (Crataegus spp.) attractive to hawthorn-origin Rhagoletis pomonella flies. J. Chem. Ecol. 29:321-336.

ReED, H. C., and LANDOLT, P. J. 2002. Attraction of mated female codling moths (Lepidoptera: Tortricidae) to apples and apple odor in a flight tunnel. Florida Entomol. 85:324-329.

Ridgway, R. L., Silverstein, R. M., and InSCOE, M. N. 1990. Behavior-modifying Chemicals for Insect Management: Applications of Pheromones and Other Attractants. Marcel Dekker, New York, NY.

Roelofs, W. L., Tette, J. P., Taschenberg, E. F. , and Comeau, A. 1971. Sex pheromone of the grape berry moth: identification by classical and electroantennogram methods, and field tests. J. Insect Physiol. 17:2235-2243.

SANDERS, C. J., LuCUiK, G. S., and FletChER, R. M. 1981. Response of male spruce budworm (Lepidoptera: Tortricidae) to different concentrations of sex pheromone as measured in a sustainedflight wind tunnel. Can. Entomol. 113:943-948.

Sas Institute. 2006. The GLIMMIX Procedure. $<$ http://www.sas.com>.

TASCHENBERG, E. F. 1945. The biology and control of the grape berry moth Polychrosis vineana (Clemens). PhD Dissertation, Cornell University, Ithaca, NY.

Tasin, M., Anfora, G., Ioriatti, C., Carlin, S., De Cristofaro, A., Schmidt, S., Bengtsson, M., Versini, G., and Witzgall, P. 2005. Antennal and behavioral responses of grapevine moth Lobesia botrana females to volatiles from grapevine. J. Chem. Ecol. 31:77-87.

Tasin, M., Backman, A. C., Bengtsson, M., Ioriatti, C., and WitzGall, P. 2006a. Essential host plant cues in the grapevine moth. Naturwissenschaften 93:141-144.
TAsin, M., Backman, A. C., Bengtsson, M., VAREla, N., Ioriatti, C., and WitzGall, P. 2006b. Wind tunnel attraction of grapevine moth females, Lobesia botrana, to natural and artificial grape odour. Chemoecology 16:87-92.

TAsin, M., BaCKMan, A.-C., Coracini, M., CASAdo, D., IoriatTi, C., and WitzGall, P. 2007. Synergism and redundancy in a plant volatile blend attracting grapevine moth females. Phytochemistry 68:203-209.

Thompson, J. N., and Pellmyr, O. 1991. Evolution of oviposition behavior and host preference in Lepidoptera. Annu. Rev. Entomol. 36:65-89.

VAN DER GEeST, L. P. S., and EVENHUIS, H. H. 1991. Tortricid pests. Their Biology, Natural Enemies and Control. Elsevier, New York, NY.

VICKERS, N. J., and BAKER, T. C. 1992. Male Heliothis virescens maintain upwind flight in response to experimentally pulsed filaments of their sex pheromone (Lepidoptera, Noctuidae). $J$. Insect Behavior 5:669-687.

Wallace, E. K., Albert, P. J., and MCNeIl, J. N. 2004. Oviposition behavior of the eastern spruce budworm Choristoneura fumiferana (Clemens) (Lepidoptera: Tortricidae). J. Insect Behavior 17:145154.

Weigle, T., BiXBy, J., and ENGLish-Loeb, G. 1999. Reexamination of grape berry moth management practices in the Lake Erie region. 1998 New York State Fruit Project Reports Relating to IPM. NYS IPM Publication \#216. Cornell University Cooperative Extension.

Willis, M. A., and BAKER, T. C. 1984. Effects of intermittent and continuous pheromone stimulation on the flight behavior of the oriental fruit moth, Grapholita molesta. Physiol. Entomol. 9:341358.

Yang, Z. H., Casado, D., Ioriatti, C., Bengtsson, M., and WitzGall, P. 2005. Pheromone pre-exposure and mating modulate codling moth (Lepidoptera: Tortricidae) response to host plant volatiles. Agric. For. Entomol. 7:231-236.

Zhang, A. J., LinN, C., Wright, S., Prokopy, R., ReIsSig, W., and ROELOFS, W. 1999. Identification of a new blend of apple volatiles attractive to the apple maggot, Rhagoletis pomonella. J. Chem. Ecol. 25:1221-1232. 